\title{
Improving the contact resistance at low force using gold coated carbon nanotube surfaces.
}

\author{
J.W. McBride, E. M. Yunus, S.M Spearing
}

School of Engineering Sciences, University of Southampton SO17 1BJ, UK

\begin{abstract}
Investigations to determine the electrical contact performance under repeated cycles at low force conditions for carbon-nanotube (CNT) coated surfaces were performed. The surfaces under investigation consisted of multi-walled CNT synthesized on a silicon substrate and coated with a gold film. These planar surfaces were mounted on the tip of a PZT actuator and contacted with a plated Au hemispherical probe. The dynamic applied force used was $1 \mathrm{mN}$. The contact resistance $\left(R_{c}\right)$ of these surfaces was investigated with the applied force and with repeated loading cycles performed for stability testing. The surfaces were compared with a reference Au-Au contact under the same experimental conditions. This initial study shows the potential for the application of gold coated CNT surfaces as an interface in low force electrical contact applications.
\end{abstract}

PACS. Contact force, contact resistance, carbon nanotubes, and $\mathrm{Au} /$ multi walled carbon nanotubes.

\section{Introduction}

This paper presents a study of electrical contact between surfaces under low dynamic force conditions, typically $1 \mathrm{mN}$. Such conditions are relevant to a number of microcontact applications, for example MEMS relay devices. There are a number of potential materials commonly used for this application including gold, palladium and platinum [1]. The weakness of such materials is that they are relatively soft and wear easily. Other materials which are of interest on MEMS relay's micro-contact include silicon carbide and diamond films. Both have high moduli but low electrical conductivity. The latter makes them unsuitable for electrical contact applications. There have been attempts to increase the conductivity. When doping $\mathrm{SiC}$ film with NH3 the resistivity drops to $1 \times 10^{-4} \Omega \mathrm{m}$ [2] and doping DLC with ruthenium the resistivity drops to $1 \times 10^{-5}$ $\Omega \mathrm{m}$ [3], however, both materials still have a high resistivity compared to gold and even gold alloys (for example Au-6.3\% Pt has a resistivity of $7.17 \times 10^{-8} \Omega \mathrm{m}$ ) [1].

A carbon nanotube (CNT) coated surface has potential as a material for MEMS relay applications specifically as a contact material because of its excellent mechanical and electrical properties. An experiment has been performed [4] to measure the contact resistance, $\mathrm{R}_{\mathrm{c}}$ between CNT coated electrodes in ambient air and in a vacuum. The author concluded that the contact resistance, $R_{c}$ was found to be much lower in ambient air $(\sim 160 \Omega)$ than in vacuum $(>4 \mathrm{k} \Omega)$. In a more recent experiment [5], Au contacts with a substrate coated with tangled single walled carbon nanotubes were investigated. The authors concluded that a tangled Single Walled Carbon Nanotube (SWCNT) film against an $\mathrm{Au}$ coated surface has a better performance than two contacting tangled films.
The following mechanical properties have been determined; CNTs tensile strength of up to $63 \mathrm{GPa}$ has been measured [6]. Experiments using an atomic force microscope were performed to measure the elastic modulus and bending strength of individual, structurally isolated, multi-wall carbon nanotubes and indicated values of 1.26 $\mathrm{TPa}$ and 14.2 GPa [7] respectively. Experiments were also conducted on CNTs using a nano-indentation apparatus and values were obtained for the bending modulus; 1.24 $\mathrm{TPa}$, axial modulus; $1.23 \mathrm{TPa}$ and wall modulus; $5.61 \mathrm{TPa}$ [8]. Another report shows that CNT's have an elastic modulus greater than $1 \mathrm{TPa}$ [9] compared to diamond, which has a modulus of $1.2 \mathrm{TPa}$.

In terms of its electrical properties, it is calculated that a 4$10 \mu \mathrm{m}$ long SWCNT with a diameter of $1.2 \mathrm{~nm}$ has a resistivity of $0.88 \times 10^{-8} \Omega \mathrm{m}$ and is thought to exhibit ballistic electrical conduction. The calculation is performed using the theory of ballistic conductors and it is assumed that the CNT is defect-free. In addition, if a CNT were to be filled with metal, to form a composite its resistivity would fall to $0.35 \times 10^{-8} \Omega \mathrm{m}$ [10]. The mechanical and electrical properties are therefore potentially comparable to diamond and gold respectively, however, as yet no experiments have been reported on CNT metal composites for micro-contact applications. In the present work a novel approach is used in which a CNT "forest" is over coated with gold, in order to provide a high conductivity surface layer with a compliant under layer.

In previous work a modified nano-indentation apparatus [11] was used to determine the contact resistance, $R_{c}$, as a function of contact force and load cycling up to ten load cycles. These initial results showed that the performance and contact resistance of $\mathrm{Au}-\mathrm{Au} / \mathrm{MWCNT}$ contact pairs is comparable to $\mathrm{Au}-\mathrm{Au}$ contact pairs and during ten load cycles of $\mathrm{Au}-\mathrm{Au} / \mathrm{MWNT}$ contact pair shows stable and constant contact resistance. The contact resistance of the $\mathrm{Au}-\mathrm{Au} / \mathrm{MWCNT}$ is typically $0.5 \Omega$ at $1 \mathrm{mN}$. This compares 
favorably with commercial MEMS relays where $1.5 \Omega$ is a common contact resistance. In this study a purpose built test system is used to investigate the dynamic performance of the surfaces under dry circuit conditions.

\section{Material preparation}

In the present study two contact pairs have been investigated; $\mathrm{Au}$ to $\mathrm{Au}$ and $\mathrm{Au}$ to $\mathrm{Au} /$ multi walled carbon nano-tubes (MWCNTs) composite. The geometry selected is a $2 \mathrm{~mm}$ diameter hemisphere contacting a flat surface. In all cases the hemisphere consists of a stainless steel base, sputter coated with $\mathrm{Au}, \sim 500 \mathrm{~nm}$ thick, with surface roughness $\mathrm{Ra} \approx 400 \mathrm{~nm}$. In the $\mathrm{Au}$ to $\mathrm{Au}$ case (Sample 1), the flat surface is a silicon ( $\mathrm{Si})$ substrate $(\sim 2 \mathrm{~mm}$ by $7 \mathrm{~mm})$, sputter coated with $\mathrm{Au} \sim 500 \mathrm{~nm}$, with a surface roughness $\mathrm{Ra} \approx 30 \mathrm{~nm}$.

For the $\mathrm{Au}$ to $\mathrm{Au} / \mathrm{MWCNT}$ case (Sample 2), a "forest" of MWCNTs is grown on the Si wafer using thermal CVD. The catalyst used is sputter deposited $\mathrm{Fe}$ and the gaseous carbon source is ethylene. The growth temperature and time is $875^{\circ} \mathrm{C}$ and 3 minutes respectively to produce a dense forest of vertically aligned MWCNT of an average length of $\sim 50 \mu \mathrm{m}$ as shown in Fig 1. Au is then sputtered on the upper surface of the MWCNT forest to produce $\mathrm{Au} / \mathrm{MWCNT}$ composite coatings as shown in Fig 2. It is shown in Fig 3, that the Au penetrates the MWCNT surface to a depth of $\sim 4 \mu \mathrm{m}$.

\section{Experimental}

In order to determine the performance of the surfaces under repeated switching actions, an apparatus has been designed, in which a PZT actuator is used to support the planar coated surfaces as shown in Fig 4. This surface makes electrical contact with the hemispherical Au-coated probe to mimic the actuation of a MEMS relay microcontact. The apparatus has been designed to allow control of the gap and to allow the performance of the contact materials to be investigated ultimately over large numbers of switching cycles $\left(>10^{6}\right)$.

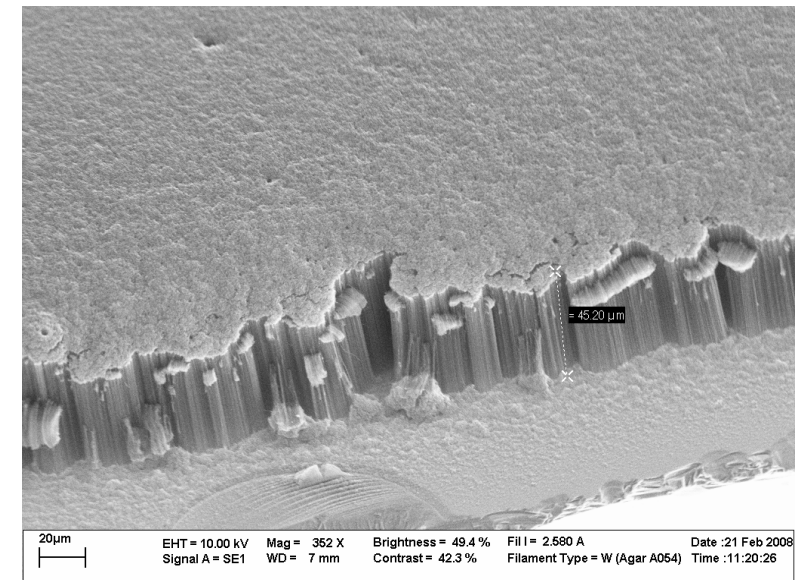

Fig. 1. Dense forest of MWCNT with average length $\sim 50 \mu \mathrm{m}$.

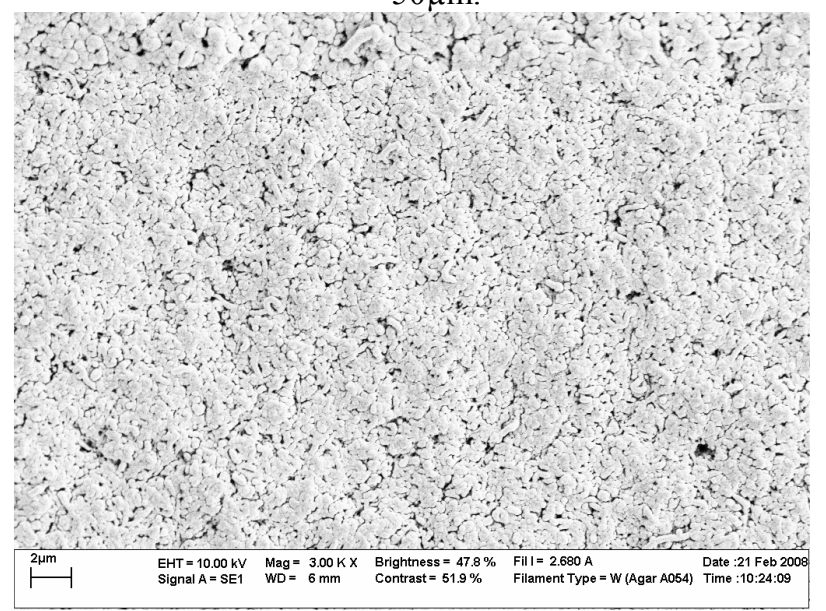

Fig. 2. Sample 2, Au/MWCNT composite contact surface.

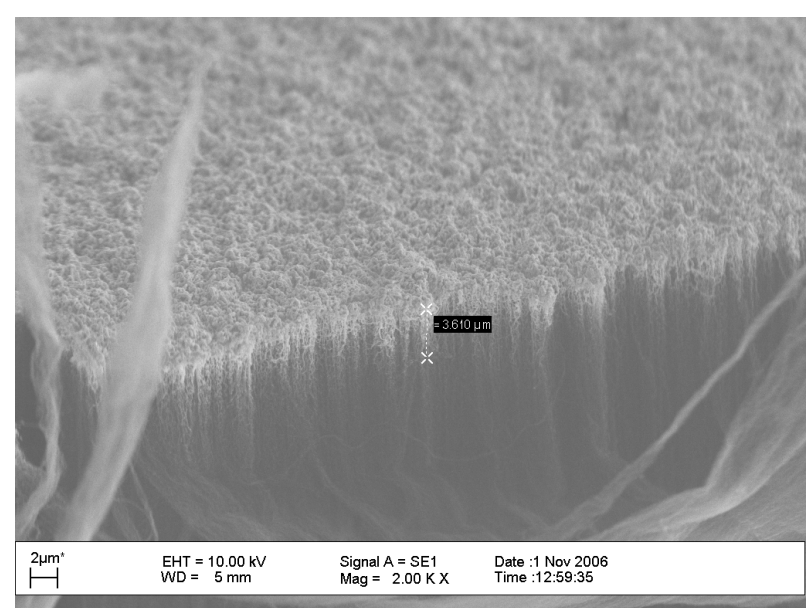

Fig. 3. Au penetration on MWCNT by sputtering. 


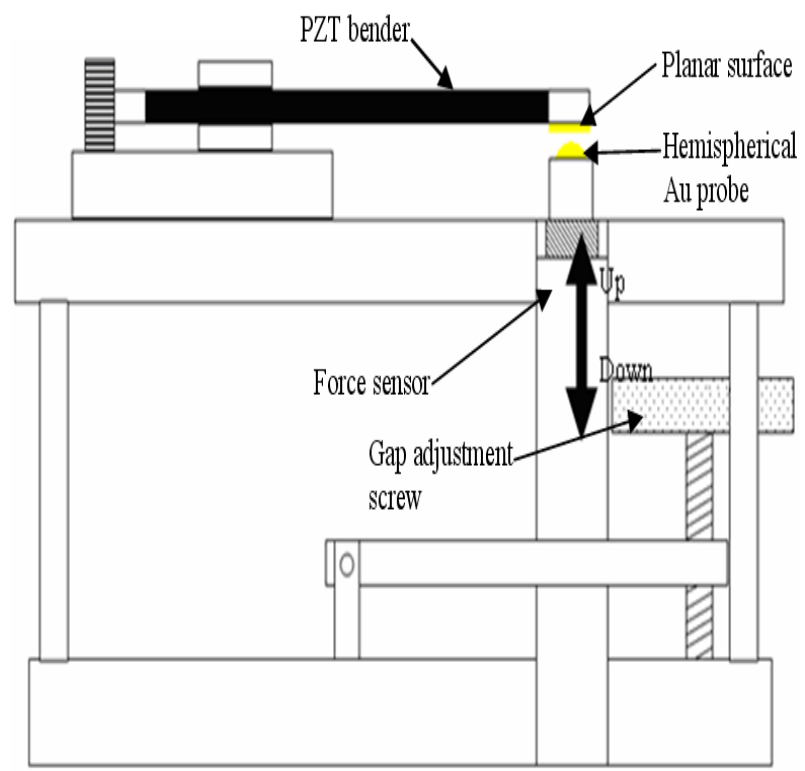

Fig. 4. Schematic side view of the test rig.

A signal generator with voltage amplification is used to actuate the PZT actuator as shown in Fig 5. The PZT actuator's layers consist of Nickel ( $1^{\text {st }}$ layer $)$, PZT material (Lead Zirconate Titanate) $\left(2^{\text {nd }}\right.$ layer $)$, Nickel ( $3^{\text {rd }}$ layer $)$ and Kovar (Nickel-Cobalt ferrous alloy, final layer). The resonance frequency of the PZT actuator is $\sim 900 \mathrm{~Hz}\left(1^{\text {st }}\right.$ harmonic). In this experiment the PZT actuator is actuated at low frequency $0.2 \mathrm{~Hz}$ to allow a quasi-static study of the contact surfaces. The dynamic force is measured using a piezoelectric force sensor [12-15] situated as shown in Figs 4 and 5. The force sensor is amplified using a charge amplifier and the dynamic force monitored.

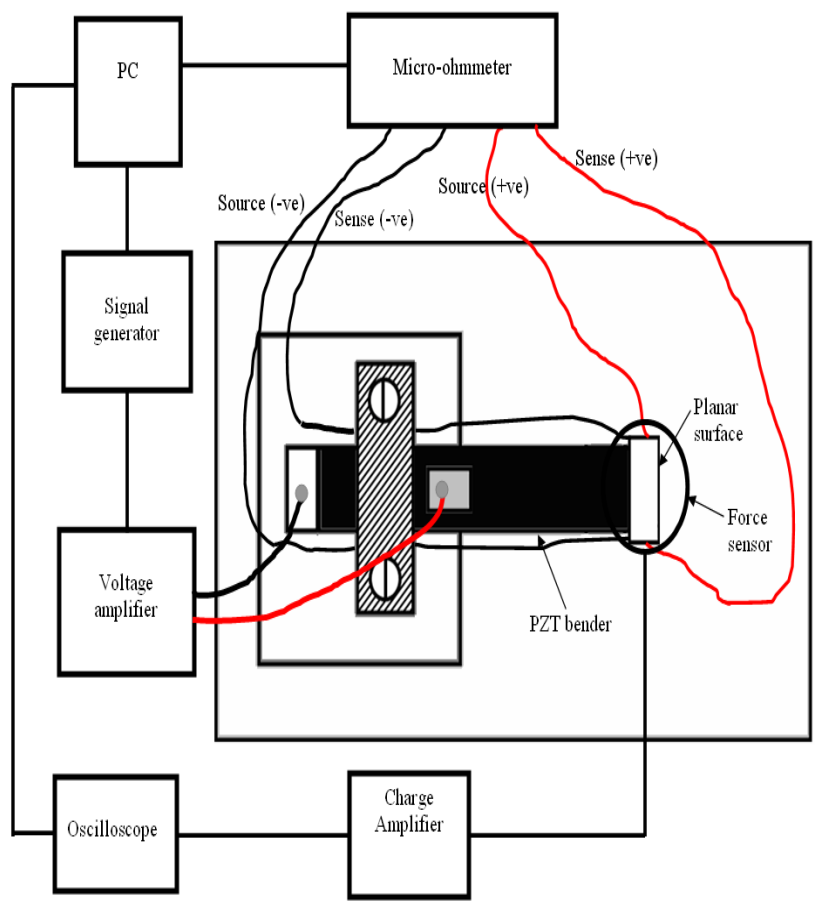

Fig. 5. Schematic top view of the test system.

There are several methods to control the applied force as follows; 1) By controlling the gap [16]. This can be achieved by turning the adjustment screw as shown in Fig 4 and the contact gap is monitored using a triangular laser, 2) By controlling the length of the actuator [14], and 3) By controlling the amplitude of the supply voltage to the actuator. In the experiment presented here all other parameters are held constant, with the contact gap used to set the contact force at $1 \mathrm{mN}$.

The contact resistance, $R_{c}$ is measured using the 4 wiremeasurement methods as shown in Fig 5 and 6. The DC current source across the planar coated surfaces and microcontact is set at $1 \mathrm{~mA}$ using a Keithley 580 microohmmeter. The number of cycles and contact resistance can be controlled and extracted by using the control and data acquisition program. The apparatus is enclosed and held at ambient air and room temperature.

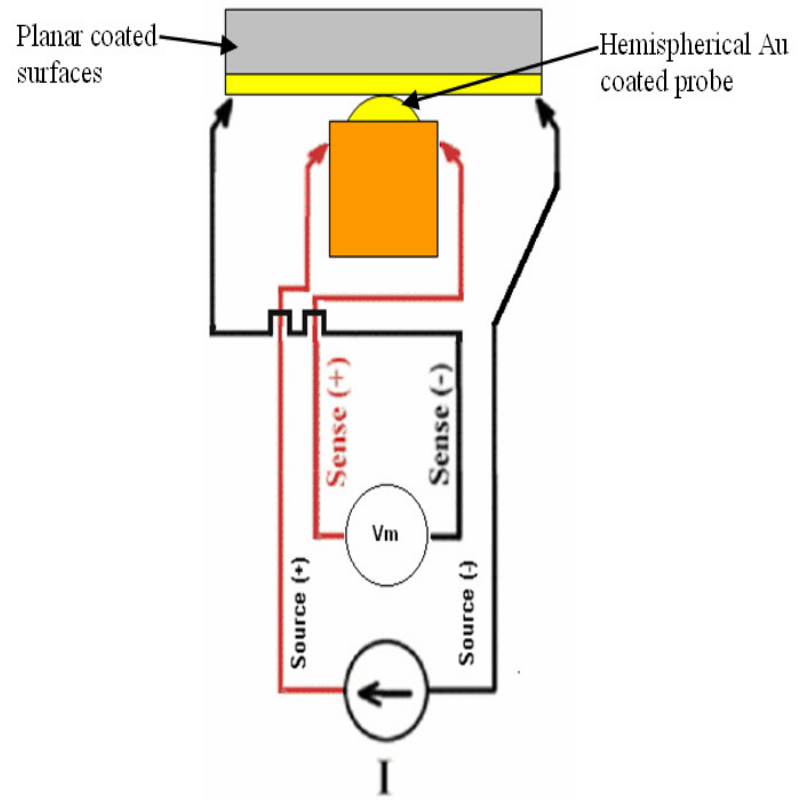

Fig. 6. Schematic of contact zone with its electrode and $R_{c}$ measurement.

In this experiment, the PZT actuator is actuated up to 1000 cycles at $0.2 \mathrm{~Hz}$ under dry circuit conditions (maximum supply of $20 \mathrm{mV}$ at $1 \mathrm{~mA}$ ) with the contact resistance $R_{c}$ measured simultaneously. The aim of this initial study is to determine the stability of the contact surfaces, prior to longer duration testing at higher frequencies, an applied force of $1 \mathrm{mN}$ is used for consistency with previous results using a nano-indenter, [11]. The coated planar surface and 
Au ball are brought into contact at $0.2 \mathrm{~Hz}$ using an applied square wave form, and the gap and amplitude adjusted so that a maximum load of $1 \mathrm{mN}$ is reached. The targeted load is applied for $\sim 3$ seconds so that a representative average contact resistance value can be determined. Fig 7 shows an example of the load history over a period of time.

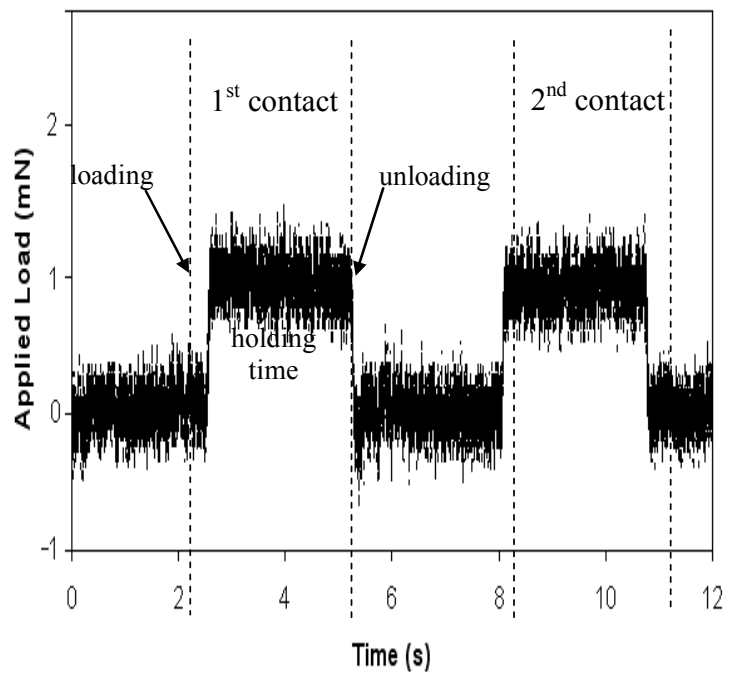

Fig. 7. Example of load cycles $(0.2 \mathrm{~Hz})$ for an $\mathrm{Au}-\mathrm{Au}$ contact pair at $1 \mathrm{mN}$.

The performance of the $\mathrm{Au}-\mathrm{Au} / \mathrm{MWCNT}$ surfaces is compared to a reference $\mathrm{Au}-\mathrm{Au}$ contact pair under the same experimental conditions in order to assess their mechanical and electrical stability. A TaiCaan Technologies XYRIS 4000CL laser scanner is used to confirm any changes on the contact surfaces samples such as degradation and wear.

\section{Results and discussion}

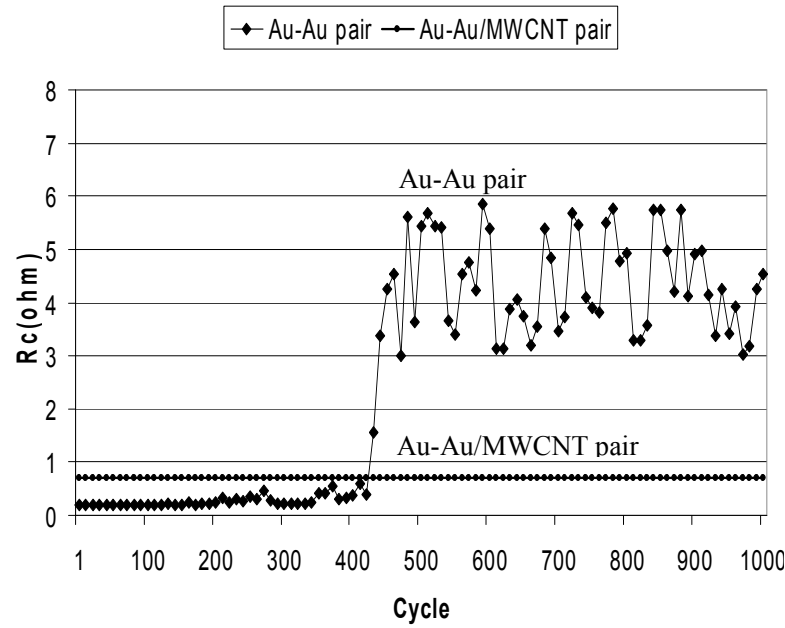

Fig. 8. Cyclic contact resistance of $\mathrm{Au}-\mathrm{Au}$ and $\mathrm{Au}-$ $\mathrm{Au} / \mathrm{MWNT}$ contact pairs.
Fig 8 shows the contact resistance of $\mathrm{Au}-\mathrm{Au}$ and $\mathrm{Au}-$ $\mathrm{Au} / \mathrm{MWCNT}$ pairs over 1000 load cycles at a maximum (quasi static) applied load of $1 \mathrm{mN}$. The contact resistance of the $\mathrm{Au}-\mathrm{Au}$ pair is initially $\sim 0.2 \Omega$ and increases rapidly to $4-6 \Omega$ at 450 cycles. Under dry circuit conditions the contacts are unlikely to degrade by "hot-switching", therefore the increase in contact resistance is solely due to the mechanical deterioration of the $\mathrm{Au}-\mathrm{Au}$ contact pair surfaces, reflecting the recognized problems of using soft metals for electrical contacts on a hard substrate. The reason for the sharp increase in $R_{c}$ of $\mathrm{Au}-\mathrm{Au}$ pair at $\sim 430$ cycles is believed to be due to the initial smoothing of the $\mathrm{Au}$ surfaces which leads to increased adhesion [17]. The smoothing is the result of the repeated impacts and timedependent deformation of the Au. Fig 9 which shows the damaged $\mathrm{Au}$ surface planar for the Au-Au contact pair.

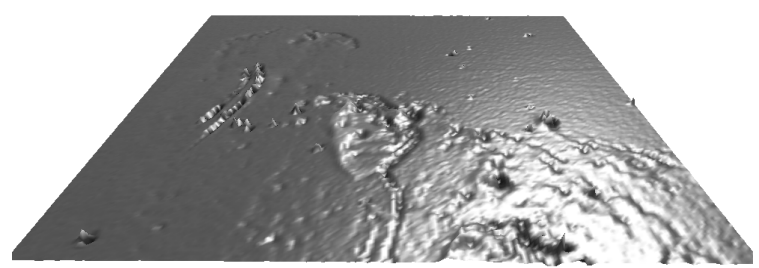

Fig. 9. Scanned image of Au planar surface 201x201(0.2mmx0.2mm) using TaiCaan (Xyris 4000CL).

The adhesive force increases with the number of cycles and is consistent with creep being one of the underlying physical mechanisms for the increase in adhesion [18]. The creep of the gold was shown in [11] during a single load cycle, as shown in Fig 10. Fig 10 shows the graph of load against displacement for an $\mathrm{Au}-\mathrm{Au}$ contact pair. The experiment was carried out by replacing the diamond tip indenter with the $\mathrm{Au}$ hemispherical probe of a nanoindentation apparatus. The curve shows there is creep, a deformation that occurs over a period of time when a material is subjected to constant stress, even at room temperature. The force cycle exhibited in Fig 11 occurs over a longer holding time scale than that used in the test procedure.

The stable contact resistance data between 1-400 cycles in Fig 8 , shows the $\mathrm{Au}-\mathrm{Au}$ interface is $\sim 0.2 \Omega$, while the $\mathrm{Au}-$ $\mathrm{Au} / \mathrm{MWCNT}$ interface is $\sim 0.5 \Omega$. If we assume the standard Holm electrical contact model (1) and (2), then it is apparent that the main difficulty in comparing the two surfaces is in the determination of the conductivity. On first inspection if we assume the conductivity is the same in both cases then the contact area in the Au-Au/MWCNT interface would be smaller, this is assumed to not the case. Firstly the conductivity of the $\mathrm{Au}-\mathrm{Au} / \mathrm{MWCNT}$ interface is expected to be a function of the CNT surface structure and the Au surface; this has yet to be defined. Secondly it has 
been suggested that the standard Holm model does not apply to thin film surfaces, [11].

$$
\begin{gathered}
R_{C} \approx \frac{\rho}{2 \alpha} \\
A_{C}=\pi \alpha^{2}
\end{gathered}
$$

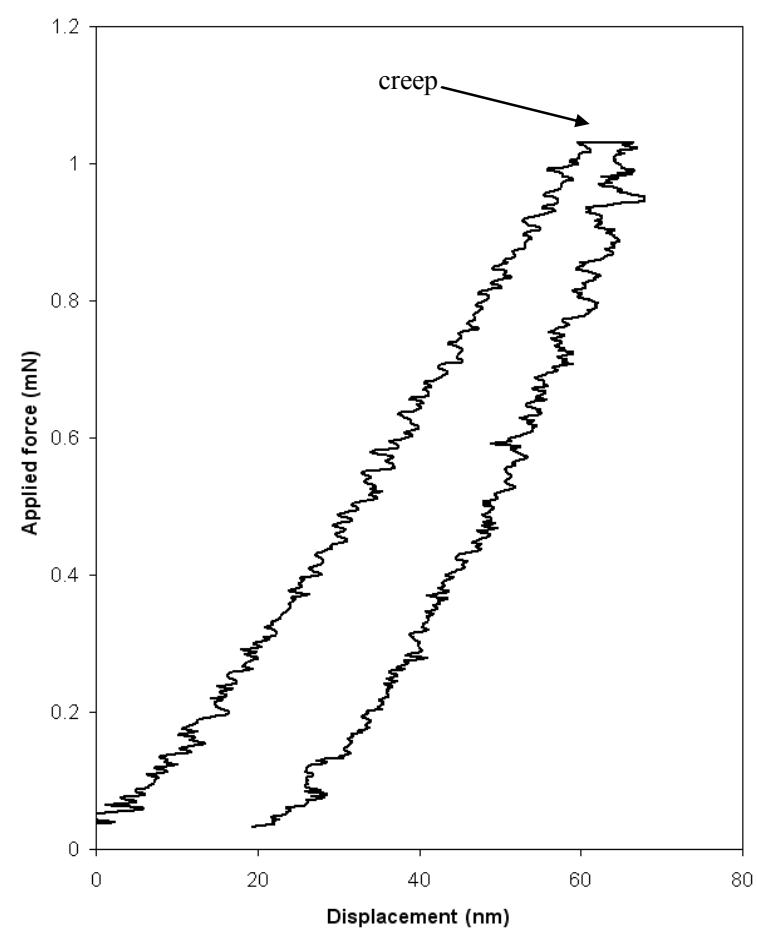

Fig. 10. Graph of load against displacement for $\mathrm{Au}-\mathrm{Au}$ contact pair.

Fig 8 also shows contact resistance of $\mathrm{Au}-\mathrm{Au} / \mathrm{MWCNT}$ contact pair. The initial contact resistance $(\sim 0.7 \Omega)$ is higher for the $\mathrm{Au}-\mathrm{Au} / \mathrm{MWNT}$ pair. The likely cause is the difference of surface roughness between $\mathrm{Au}$ and $\mathrm{Au} / \mathrm{MWCNT}$ coated planar surface and the irregularity of the $\mathrm{Au}$ film on the MWCNT. It is anticipated that this can be improved in subsequent experiments by better process control. The contact resistance is much more stable than for the Au-Au pair over the 1000 loading cycles. This is believed to be due to the Au/MWCNT surfaces conforming to the shape of the $\mathrm{Au}$ hemispherical probe. The dynamic impact on the Au hemispherical probe is absorbed by the Au/MWCNT surfaces thus reducing the wear. The sponge-like effect on Au-Au/MWCNT helps to reduce the deterioration. Furthermore, as the applied load is increased, more deflection occurs of the MWNTs closing the air gaps between the vertically aligned MWNTs thus improving the transfer of electrons [11].

Fig 11 shows a graph of load against displacement using a modified nanoindentation apparatus with $\mathrm{Au}-\mathrm{Au}$, and $\mathrm{Au}-$ $\mathrm{Au} / \mathrm{MWCNT}$ contact pair. It shows the depth of penetration during the impact. The curve for $\mathrm{Au}-$ $\mathrm{Au} / \mathrm{MWCNT}$ pair shows that there is much depth penetration compared with $\mathrm{Au}-\mathrm{Au}$ pair $(\sim 70 \mathrm{~nm}$ and $\sim 2500 \mathrm{~nm}$ respectively). Once the indentation load is removed permanent displacement can be observed $(\sim 1400$ $\mathrm{nm})$. In [11] the results show an SEM image of the Au hemispherical probe contact surface after the load cycles having some damage to the Au surfaces where many small impressions on the $\mathrm{Au}$ hemispherical probe are detected. These impressions are due to the asperities on the MWNT surfaces. Moreover when the surface roughness $\left(R_{a}\right)$ is measured in this region it has changed from $\sim 400 \mathrm{~nm}$ to $\sim 1.5 \mu \mathrm{m}$.

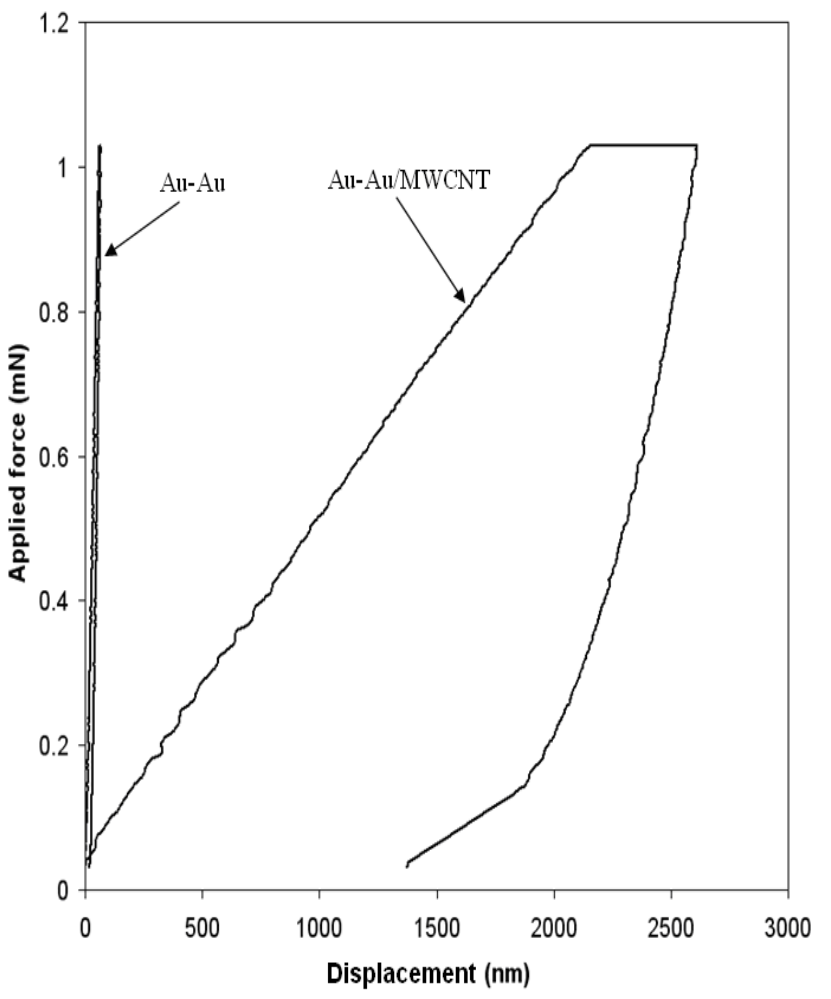

Fig. 11. Graph of load against displacement for an Au-Au, and $\mathrm{Au}-\mathrm{Au} / \mathrm{MWCNT}$ contact pair.

In addition, as the $\mathrm{Au} / \mathrm{MWNT}$ s surface conforms to the shape of the $\mathrm{Au}$ hemispherical probe it increases the contact area. There is a smoothening of the Au asperity and a significant indentation marks on the $\mathrm{Au}$ covering the surface of the $\mathrm{Au}$ hemispherical probe as shown in ' $A$ ' and ' $\mathrm{B}$ ' respectively on Fig 12. An SEM investigation has shown there to be no damage on the Au/MWCNT planar composite, further suggesting that the CNT under layer has improved the mechanical integrity of the gold surface. 


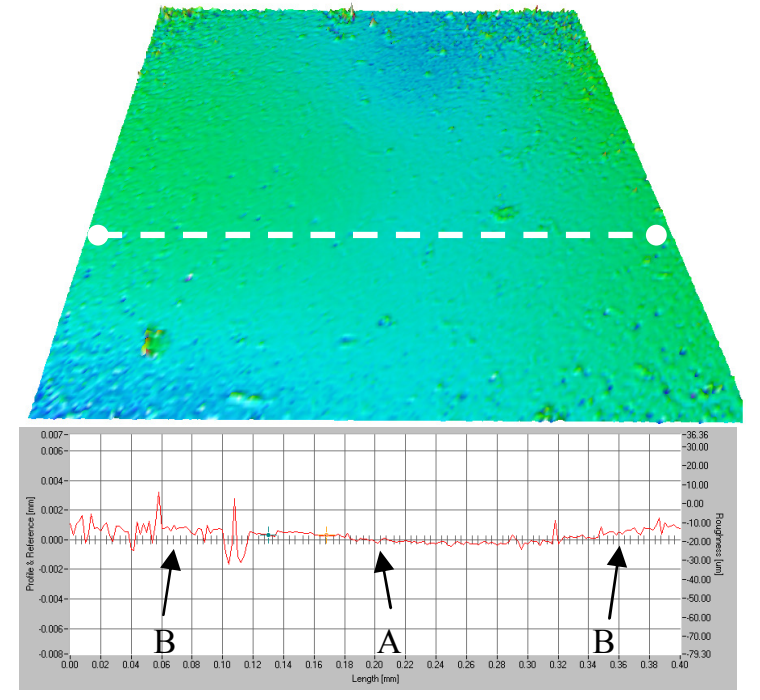

Fig. 12. Scanned image of $\mathrm{Au}$ ball for $\mathrm{Au}-\mathrm{Au} / \mathrm{MWCNT}$ with the sphere removed, contact pair $301 \times 301$ (0.4mmx0.4mm) using TaiCaan (Xyris 4000CL).

\section{Conclusion}

The applied cyclic load and contact resistance between $\mathrm{Au}-$ $\mathrm{Au} / \mathrm{MWCNT}$ composite contact pairs was investigated using a PZT actuator apparatus and $R_{c}$ measurement methods. This contact pair combination was compared with an Au-Au contact pair. Over 1000 load cycles the Au$\mathrm{Au} / \mathrm{MWCNT}$ contact pair demonstrated a much more stable contact resistance than $\mathrm{Au}-\mathrm{Au}$ contact pair. This improvement is believed to be due to Au/MWCNT surface conforming readily with the dynamic impact of the $\mathrm{Au}$ hemispherical probe thus decreasing the tendency of smoothing and adhesion that damages the surfaces.

\section{Acknowledgments}

The authors thank Dr. David Smith of the School of Physics and Astronomy, for providing the facilities for developing the MWCNT deposition, and to Mr. Tim Hartley for his dedication in designing and fabricating the test apparatus.

\section{References}

[1] Coutu, R. A., Kladitis, P. E., Leedy, K. D. and Crane, R. L., 2004, "Selecting Metal Alloy Electric Contact Materials for MEMS Switches," Journal of Micromechanics and Microengineering, (14) pp. 1157-1164.

[2] Gao, D., Wijesundara, M. B. J., Carraro, C., Low, C. W., Howe, R. T. and Maboudian, R., 2003, "High Modulus Polycrystalline 3C-SiC Technology for RF MEMS," The 2th International Conference on Solid State Sensors, Actuators and Mircosystems, 3D3.4, pp. 1160-1163.
[3] Lian, G. D., Dickey, E. C., Ueno, M. and Sunkara, M. K., 2002, "Ru-doped Nanostructured Carbon Films," Diamond and Related Materials, 11, pp. 1890-1896.

[4] Tzeng, Y., Chen, Y. and Liu, C., 2003, "Electrical contacts between carbon-nanotube coated electrodes, " Diamond and Related Materials, 12, pp. 774-779.

[5] Yaglioglu, O., Hart, A. J., Martens, R. and Slocum, A. H., 2006, "Method of characterizing electrical contact properties of carbon nanotube coated surfaces," Review of Scientific Instruments, 77, pp 095105/1-3.

[6] Yu, M. F., Lourie, O., Dyer, M. J., Moloni, K., Kelly, T. F. and Ruoff, R.S., 2000, "Strength and Breaking Mechanism of Multiwalled Carbon Nanotubes Under Tensile Load," Science, 287(5453), pp. $637-640$.

[7] Wong EW, Sheehan PE, Lieber CM, 1997 "Nanobeam Mechanics: Elasticity, Strength, and Toughness of Nanorods and Nanotubes, " Science, 277, pp. 1971-5.

[8] Qi, H.J., Teo, K.B.K., Lau, K.K.S., Boyce, M.C., Milne, W.I., Robertson, J. and Gleason, K.K., 2003, "Determination of Mechanical Properties of Carbon Nanotubes and Vertically Aligned Carbon Nanotube forests using Nanoindentation," Journal of Mechanics and Physics of Solids, 51, pp. 2213-2237.

[9] Thostenson, E. T., Ren, Z. and Chou, T.W., 2001, "Advances in the Science and Technology of Carbon Nanotubes and their Composites: A review," Composites Science and Technology, 61, pp. 1899-1912.

[10] Hjortstam, O., Isberg, P., Söderholm, S. and Dai, H., 2004, "Can we achieve ultra-low resistivity in carbon nanotubebased metal composites?" Journal of Applied Physics A, Materials Science \& Processing, 78, pp. 1175-1179.

[11] Yunus, E.M., McBride, J.W., and Spearing, S.M., 2007, "The Relationship between Contact Resistance and Contact Force on Au coated Carbon Nanotubes surfaces, " Electrical Contact, Proceedings of The 53rd IEEE Holm Conference on Electrical Contacts, Vol.6.4, pp.167-174.

[12] Beckwith, T.G., Marangoni, R.D. and Lienhard V, J.H., 5th Ed, 1993, "Mechanical Measurements," Addison-Wesley Publishing Company.

[13] Usher, M.J., 1985, "Sensors and Transducers, " Macmillan.

[14] Duval, F.F.C., Wilson, S.A., Ensell, G., Evanno, N.M.P., Cain, M.G., and Whatmore, R.W., 2007, "Characterisation of PZT thin film micro-actuators using a silicon micro-force sensor," Sensors and Actuators A 133, pp. 35-44.

[15] Dong, W., Lu, X., Cui, Y., Wang, J. and Liu, M. 2007, "Fabrication and Characterization of microcantilever integrated with PZT thin film sensor and actuator," Thin Solid Films, 515, pp. 8544-8548.

[16] Young, C. W. 1989, “Roark's: Formulas for Stress \& Strain," McGRAW-HILL International Edition, General Engineering Series.

[17] Patton, S.T. and Zabinski, J. S., 2005, "Fundamental studies of Au contacts in MEMS RF switches," Tribology Letters, Vol 18, No.2, pp. 215-230.

[18] Gregori, G. and Clarke, D.R., 2006, "The interrelation between adhesion, contact creep, and roughness on the life of gold contacts in radio-frequency microswitches, " Journal of Applied Physics, 100, pp. 09494-1-10. 